\title{
Impact of health care insurance on overall survival of patients with multiple myeloma and monoclonal gammopathy of undetermined significance
}

\author{
Srinivas S. Devarakonda ${ }^{1}$, Runhua Shi', Ellen Friday¹, Reinhold Munker ${ }^{2}$, Jonathan Glass ${ }^{1}$, Francesco Turturro ${ }^{1,3}$ \\ ${ }^{\prime}$ Department of Medicine, Feist-Weiller Cancer Center, Louisiana State University Health Sciences Center, Shreveport, LA 71103, USA. \\ ${ }^{2}$ Department of Medicine, Louisiana State University, New Orleans, LA 71103, USA. \\ ${ }^{3}$ Department of Lymphoma/Myeloma, MD Anderson Cancer Center, Houston, TX 77030, USA.
}

Correspondence to: Dr. Srinivas S. Devarakonda, Department of Medicine, Feist-Weiller Cancer Center, Louisiana State University Health Sciences Center, 1501 Kings Highway, Shreveport, LA 71103, USA. E-mail: sdeva1@1suhsc.edu

How to cite this article: Devarakonda SS, Shi R, Friday E, Munker R, Glass J, Turturro F. Impact of health care insurance on overall survival of patients with multiple myeloma and monoclonal gammopathy of undetermined significance. J Cancer Metastasis Treat 2017;3:100-4.

Article history:

Received: 13-03-2017

Accepted: 22-05-2017

Published: 09-06-2017

Key words:

Multiple myeloma, monoclonal gammopathy of undetermined significance, health care,

health insurance, outcomes,

survival

\begin{abstract}
\end{abstract}
\section{INTRODUCTION}

Multiple myeloma (MM) is the second most common hematological malignancy in the United States and the most common hematological malignancy in African-
Americans. ${ }^{[1,2]} \mathrm{MM}$ is preceded by an asymptomatic premalignant proliferation of plasma cells termed "monoclonal gammopathy of uncertain significance (MGUS)". ${ }^{[3-6]}$ MM and MGUS are twice as common in African-Americans as in Caucasians and more

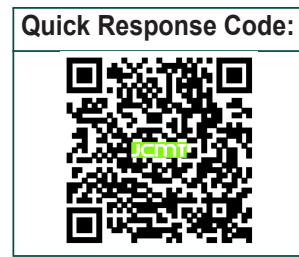


common in males than females. ${ }^{[7-10]}$ The prevalence of MGUS is $3 \%$ in people older than 50 years and patients with MGUS have an annual $1 \%$ risk of progression to MM or related malignant disorder. ${ }^{[11-14]}$ Advances in therapeutic options such as proteasome inhibitors, immune modulatory drugs (IMDs) and stem cell transplantation (SCT) have improved the prognosis and survival of patients with MM. ${ }^{15,16]}$ Several drugs belonging to the class of proteasome inhibitors such as Bortezomib, Carfilzomib, Ixazomib, immunomodulators such as Lenalidomide, Pomalidomide and monoclonal antibodies such as Daratumumab and Elotuzumab have changed the landscape of treatment of multiple myeloma in the last decade. Patients with MGUS undergo active surveillance for progression to $\mathrm{MM}$ and do not receive active treatment.

The impact of socioeconomic status has been studied in several solid organ malignancies including breast, colorectal, prostate and pancreatic cancer. Health care insurance has been shown to result in positive outcomes in patients diagnosed with these malignancies. ${ }^{[17,18]}$ Health insurance improves access to health care, early diagnosis and access to several advanced therapeutic options. Several studies have explored the influence of socioeconomic status on the survival of patients with leukemia and MM. ${ }^{[19,20]}$ However, these studies have not examined the effect of insurance on the outcome of these hematologic malignancies. We attempted to study the effect of health care insurance; in particular, on the outcomes of patients diagnosed with MM and MGUS at Louisiana State University Health Sciences Center (LSUHSC), Shreveport, LA, where approximately half the patient population is uninsured.

\section{METHODS}

We conducted a retrospective study of all the patients at our institution diagnosed with and treated for MM and MGUS between the years 1997 and 2012. MM and MGUS were defined using the International Classification of Disease for Oncology, 3rd edition (ICD-O-3) codes. All the data were obtained from the electronic medical records of the cancer center at our institution and Social Security death index. Approval for accessing the patient information was obtained from the Institutional Review Board (IRB) at our institution. Date of diagnosis, demographic factors such as age, gender, race, health care insurance status and staging at the time of diagnosis were available for each case. Durie-Salmon staging was used for staging the patients with MM. Patients with MM were classified as having high risk and standard risk disease according to the Mayo clinic risk stratification for myeloma. ${ }^{[21]}$
Medical insurance status at the time of diagnosis was defined as funded if a patient had Medicaid, Medicare or commercial insurance and non-funded if the patient was coded as free-care or self-pay.

Descriptive statistics were used to describe the data. Product limit methods were used to estimate survival and Log rank test was used to compare survival difference for each factor. Statistical software $S S^{\circledR} 9.3$ (SAS institute, Gary, NC) were used in the statistical data analysis. A $P$-value of $<0.05$ was considered the threshold for statistical significance.

\section{RESULTS}

The medical records were reviewed of 257 patients with MM or MGUS diagnosed and treated at LSUHSC from 1997-2012. Of these patients $208(80.9 \%)$ had MM and $49(19.1 \%)$ had MGUS. The median age at diagnosis was 60 years for MM and 59 years for MGUS patients. Of all the patients diagnosed with MM and MGUS, $92(37 \%)$ were Caucasians and $165(63 \%)$ were African-Americans. There was a slight female predominance with 114 male (44\%) and 143 female $(56 \%)$ patients [Table 1]. Stratification of the patients according to the stage of MM revealed $49(23.5 \%)$ to be stage $1,23(11 \%)$ to be stage $2,95(45.6 \%)$ to be stage $3 A$ and $41(19.7 \%)$ to be stage $3 B$ disease. When patients were classified according to their health care insurance status, $177(69 \%)$ were funded and $80(31 \%)$ were non-funded. At presentation, $23.6 \%$ of non-funded patients had stage $3 \mathrm{~B}$ disease compared to $18.5 \%$ in the funded group $(P=0.06)$. High-risk features were seen in $16.7 \%$ of the MM patients with insurance as compared to $27.2 \%$ of the non-funded patients $(P=0.29)$. However, the median survival was 6.2 years in the funded group compared to 3.8 years in the non-funded group $(P<0.001)$ [Figure 1] with a 5 -year survival for MM patients of $60 \%$ in the funded group compared to $42 \%$ in the non-funded group. The 5 -year survival for MGUS was $95 \%$ for patients with insurance and $62 \%$ for patients without insurance $(P$ $=0.03)$. When the effect of race was examined the overall survival in the Caucasian group with MM was

Table 1: Patient demographics

\begin{tabular}{lcc}
\hline & MM & MGUS \\
\hline Age, years & $59.7(21.2-93.3)$ & $61.0(41.6-83.3)$ \\
Race & $143(66.5 \%)$ & $20(50 \%)$ \\
AA & $72(33.5 \%)$ & $20(50 \%)$ \\
Cauc & $95(44.2 \%)$ & $19(47.5 \%)$ \\
Gender & $120(55.8 \%)$ & $21(52.5 \%)$ \\
$\quad$ Male & & \\
Female & $121(56.28 \%)$ & $25(62.5 \%)$ \\
Insurance & $94(43.72 \%)$ & $15(37.5 \%)$ \\
$\quad$ Funded & Non-funded &
\end{tabular}

MM: multiple myeloma; MGUS: monoclonal gammopathy of undetermined significance; AA: African American; Cauc: Caucasian 
noted to be 6.2 years compared to 5.1 years in the African American group $(P=0.517)$. Likewise, gender had little impact on survival as there was only a slight but not statistically significant increase in survival in female patients with $\mathrm{MM}$ with a mean survival of 5.4 years for females vs. 5.1 years for males $(P=0.748)$. Follow up of patients with MGUS at 8.3 years revealed that $73 \%$ of funded patients were alive as compared to $50 \%$ in the non-funded group $(P=0.03)$. The overall survival of patients when classified according to stage was 12.8 years for stage 1, 4.3 years for stage 2, 5.1 years for stage $3 \mathrm{~A}$ and 3.3 years for stage $3 \mathrm{~B}(P<$ 0.0001). Although the stage distribution was similar in the funded and non-funded groups at the time of diagnosis, within each stage the funded patients had improved survival. $P$-values to compare the survival difference between funded and non-funded groups for stage $1,2,3 a$, and $3 b$ were $0.098,0.267,0.039$, and 0.123 , respectively.

\section{DISCUSSION}

We have conducted the first study to examine the

A

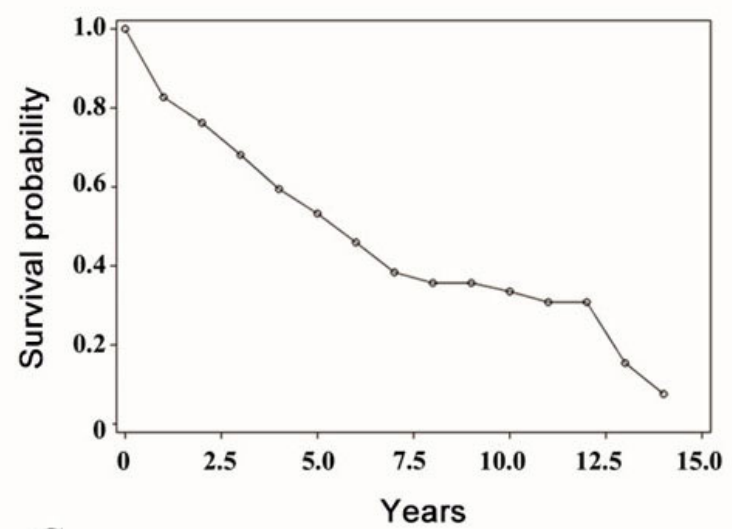

C

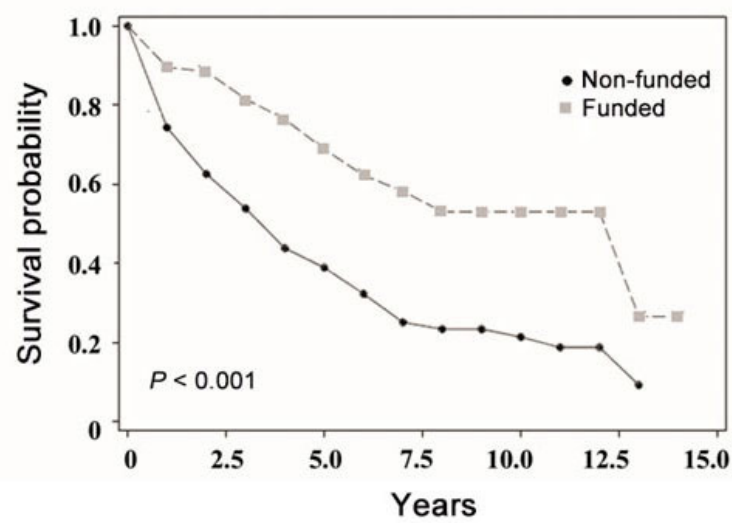

impact of health care insurance on the outcomes of patients with multiple myeloma. Previous studies examined the role of poverty and socioeconomic status on the outcome of patients with MM but until now there was no study looking into the role of health care insurance on the survival of patients with this disease. In our study, we found that the funded patients diagnosed with MM and MGUS, the precursor of MM, have significantly better median, 5-year and overall survivals than patients without insurance. The insurance status was analyzed at the time of diagnosis and did not take into account change of insurance status during the course of the illness. It could be presumed that funded patients had better access to medical care, thereby allowing for earlier diagnosis; less advanced disease, and hence improved survival. However, there was no statistically significant difference in the distribution of disease stage between the funded and non-funded groups. Another feature of MM that could potentially influence the outcomes is the biology of the disease as reflected by the presence of disease risk features. However, the Mayo Clinic risk stratification criteria were similarly distributed between

\section{B}

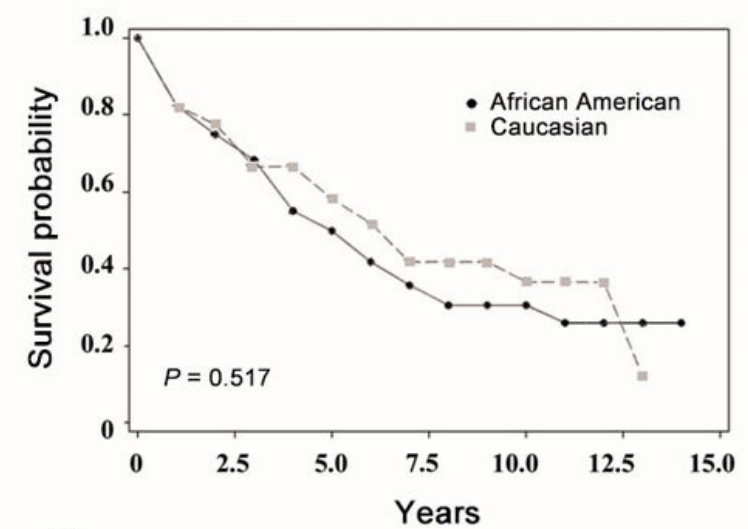

D

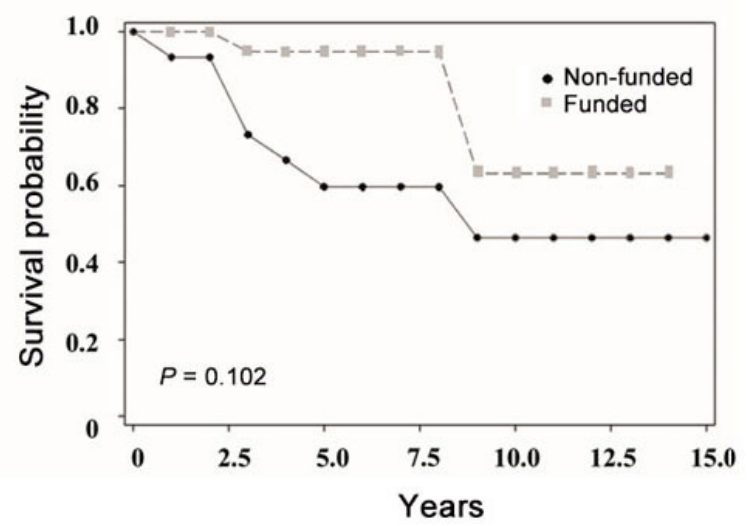

Figure 1: Two hundred and fifty-seven patients with multiple myeloma or MGUS diagnosed and treated. (A) Overall survival of patients with multiple myeloma; (B) comparison of overall survival of multiple myeloma based on race; (C) comparison of overall survival of multiple myeloma based on funding; (D) comparison of overall survival of MGUS based on funding. MGUS: monoclonal gammopathy of undetermined significance 
the funded and non-funded patients.

While insurance did not appear to affect various parameters at the time of diagnosis, it is possible that subsequent treatment might be adversely affected. However, at our institution the same physicians treat patients in the same clinic setting, with the same treatment protocols regardless of payer status. As the possibility of treatment differences between the two groups leading to improved survival of one group over the other seems less likely, our results suggest that having health care insurance, with easier access to health care, is probably an independent predictor of survival in patients with MM and MGUS. We are currently investigating whether comorbid conditions at the time of diagnosis are affecting response to therapy and subsequent outcomes. It could be argued that the death of patients with MGUS is usually more likely to occur from comorbidities than from progression to $\mathrm{MM}$, as the conversion rate of MGUS to MM is $1 \%$ per year, and hence since the impact of health care insurance on survival is greater in MM than MGUS, the effects are more likely to be direct (diagnosing earlier disease progression), particularly in view of the recent knowledge that $\mathrm{MM}$ is inevitably preceded by MGUS. ${ }^{[3,4]}$

The survival differences relative to race and gender were not statistically significant. Prior studies have demonstrated either no difference or improved survival for one group or the other. Most recently, analysis of the SEER data demonstrated superior survivals in African Americans but with improving survival in Caucasians, but not African Americans, with time over the study period of 1973 to $2005 .^{[6,7]}$ The last observation suggested differential access to newer therapies. However, we noted that survival was similar for all stages of disease and in a preliminary review of treatments that there were no differences in use of newer modalities. Our results suggest that the effects of socioeconomic status on outcomes can be overcome by the expertise of an academic center where patients are treated by faculty dedicated to the treatment of MM.

The strengths of our study are that it showed consistent results in regards to the impact of health care insurance in patients with both MM and MGUS. Our finding is not the consequence of differences in stage distribution or high-risk features, adding impetus to the independent effect of insurance status on the outcomes of MM. As the patients were treated in a health care facility with equal access regardless of payer status, we eliminated the confounding effects of the influence of advanced therapeutic options such as SCT and IMDs. As the patients came from about 60 of Louisiana's 64 parishes (counties) it is difficult to ascertain the exact causes of death of all the patients, thereby making the calculation of disease specific survival rates difficult. With the advent of health care reform and insurance coverage for nearly all Americans, it is possible that outcome differences will be minimized in the future. However, the effects of insurance status on outcome presumably reflects the effect of various exogenous factors such as the lifestyle factors including diet, exercise, alcohol, tobacco, etc. as well as compliance issues and hence as these factors will not be eliminated by health care insurance it is important to understand how they influence the disease outcome.

In conclusion, our study showed that patients with multiple myeloma and MGUS with health care insurance have longer overall survival when compared to non-funded patients. There was no difference in survival in our patient population based on race or gender. Further studies are needed to explore the various factors through which health care insurance impacts the disease outcomes.

\section{Authors' contributions}

Designed the entire project, reviewed the data and drafted the manuscript: S.S. Devarakonda, F. Turturro, J. Glass

Contributed to finalizing the manuscript: R. Munker Analyzed the data as cancer epidemiologist: R. Shi Assisted in the preparation of the manuscript: E. Friday

\section{Acknowledgments}

We are grateful to all the patients and their families who have contributed to the data of this work.

\section{Financial support and sponsorship} None.

\section{Conflicts of interest}

There are no conflicts of interest.

\section{Patient consent}

Waiver of consent and authorization was obtained from LSU Health Internal Review Board.

\section{Ethics approval}

The study has been approved by LSU Health Internal Review Board, IRB approval \# E10-005.

\section{REFERENCES}

1. Jemal A, Siegel R, Ward E, Hao Y, Xu J, Thun MJ. Cancer statistics, 2009. CA Cancer J Clin 2009;59:225-49.

2. Benjamin M, Reddy S, Brawley OW. Myeloma and race: a review of 
literature. Cancer Metastasis Rev 2003;22:87-93.

3. Landgren O, Kyle RA, Pfeiffer RM, Katzmann JA, Caporaso NE, Hayes RB, Dispenzieri A, Kumar S, Clark RJ, Baris D, Hoover R, Rajkumar SV. Monoclonal gammopathy of undetermined significance (MGUS) consistently precedes multiple myeloma: a prospective study. Blood 2009;113:5412-7.

4. Weiss BM, Abadie J, Verma P, Howard RS, Kuehl WM. A monoclonal gammopathy precedes multiple myeloma in most patients. Blood 2009;113;5418-22

5. Sigurdardottir EE, Turesson I, Lund SH, Lindqvist EK, Mailankody S, Korde N, Björkholm M, Landgren O, Kristinsson SY. The role of diagnosis and clinical follow-up of monoclonal gammopathy of undetermined significance on survival in multiple myeloma. JAMA Oncol 2015;1:168-74.

6. Dhodapkar MV. MGUS to myeloma: a mysterious gammopathy of underexplored significance. Blood 2016;128:2599-606.

7. Waxman AJ, Mink PJ, Devesa SS, Anderson WF, Weiss BM, Kristinsson SY, McGlynn KA, Landgren O. Racial disparities in incidence and outcome in multiple myeloma: a population-based study. Blood 2010;116:5501-6.

8. Landgren O, Weiss B. Patterns of monoclonal gammopathy of undetermined significance and multiple myeloma in various ethnic/ racial groups: support for genetic factors in pathogenesis. Leukemia 2009;23:1691-7

9. Walker B, Figgs L, Zahm S. Differences in cancer incidence, mortality, and survival between African Americans and whites. Environ Health Perspect 1995;8:275-81

10. Altekruse SF, Kosary CL, Krapcho M, Neyman N, Aminou R, Waldron W, Ruhl J, Howlader N, Tatalovich Z, Cho H, Mariotto A, Eisner MP, Lewis DR, Cronin K, Chen HS, Feuer EJ, Stinchcomb DG, Edwards BK, editors. SEER Cancer Statistics Review 1975-2007. Bethesda, MD: National Cancer Institute; 2010. Available from: http://seer. cancer.gov/csr/1975_2007/</csr/1975_2007/>, based on November 2009 SEER data submission, posted to the SEER web site.

11. Schaar CG, le Cessie S, Snijder S, Franck PF, Wijermans PW, Ong C, Kluin-Nelemans H. Long-term follow-up of a population based cohort with monoclonal proteinaemia. Br J Haematol 2009;144:176-84.

12. Landgren O, Katzmann JA, Hsing AW, Pfeiffer RM, Kyle RA, Yeboah
ED, Biritwum RB, Tettey Y, Adjei AA, Larson DR, Dispenzieri A, Melton LJ 3rd, Goldin LR, McMaster ML, Caporaso NE, Rajkumar SV. Prevalence of monoclonal gammopathy of undetermined significance among men in Ghana. Mayo Clin Proc 2007;82:1468-73.

13. Kyle RA, Therneau TM, Rajkumar SV, Larson DR, Plevak MF, Offord JR, Dispenzieri A, Katzmann JA, Melton LJ 3rd. Prevalence of monoclonal gammopathy of undetermined significance. $N$ Engl $J$ Med 2006;354:1362-9.

14. Landgren O, Gridley G, Turesson I, Caporaso NE, Goldin LR, Baris D, Fears TR, Hoover RN, Linet MS. Risk of monoclonal gammopathy of undetermined significance (MGUS) and subsequent multiple myeloma among African American and white veterans in the United States. Blood 2006;107:904-6.

15. Munker R, Shi R, Nair B, Devarakonda S, Cotelingam JD, McLarty J, Mills GM, Glass J. The Shreveport myeloma experience: survival, risk factors and other malignancies in the age of stem cell transplantation. Acta Hematol 2016;135:146-55.

16. Kumar SK, Rajkumar SV, Dispenzieri A, Lacy MQ, Hayman SR, Buadi FK, Zeldenrust SR, Dingli D, Russell SJ, Lust JA, Greipp PR, Kyle RA, Gertz MA. Improved survival in multiple myeloma and the impact of novel therapies. Blood 2008;111:2516-20

17. Ayanian JZ, Kohler BA, Abe T, Epstein AM. The relation between health insurance coverage and clinical outcomes among women with breast cancer. N Engl J Med 1993;329:326-31.

18. Zaydfudim V, Whiteside MA, Griffin MR, Feurer ID, Wright JK, Pinson CW. Health insurance status affects staging and influences treatment strategies in patients with hepatocellular carcinoma. Ann Surg Oncol 2010;17:3104-11.

19. Kent EE, Sender LS, Largent JA, Anton-Culver H. Leukemia survival in children, adolescents and young adults: influence of socioeconomic status and other demographic factors. Cancer Causes Control 2009;20:1409-20

20. Abou-Jawde RM, Baz R, Walker E, Choueiri TK, Karam MA, Reed J, Faiman B, Hussein M. The role of race, socioeconomic status, and distance traveled on the outcome of African-American patients with multiple myeloma. Haematologica 2006;91:1410-3

21. Rajkumar SV, Kyle RA. Multiple myeloma: diagnosis and treatment Mayo Clin Proc 2005;80:1371-82. 